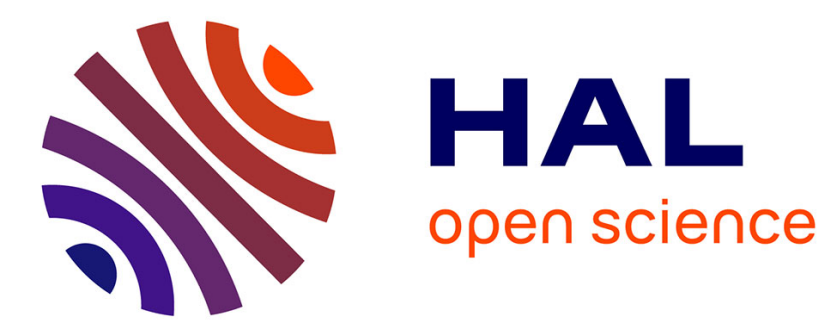

\title{
Seven steps to make travel to scientific conferences more sustainable
}

\author{
Olivier Hamant, Timothy Saunders, Virgile Viasnoff
}

\section{To cite this version:}

Olivier Hamant, Timothy Saunders, Virgile Viasnoff. Seven steps to make travel to scientific conferences more sustainable. Nature, 2019, 573 (7774), pp.451-452. 10.1038/d41586-019-02747-6 . hal02539837

\section{HAL Id: hal-02539837 \\ https://hal.inrae.fr/hal-02539837}

Submitted on 16 Dec 2020

HAL is a multi-disciplinary open access archive for the deposit and dissemination of scientific research documents, whether they are published or not. The documents may come from teaching and research institutions in France or abroad, or from public or private research centers.
L'archive ouverte pluridisciplinaire HAL, est destinée au dépôt et à la diffusion de documents scientifiques de niveau recherche, publiés ou non, émanant des établissements d'enseignement et de recherche français ou étrangers, des laboratoires publics ou privés. 


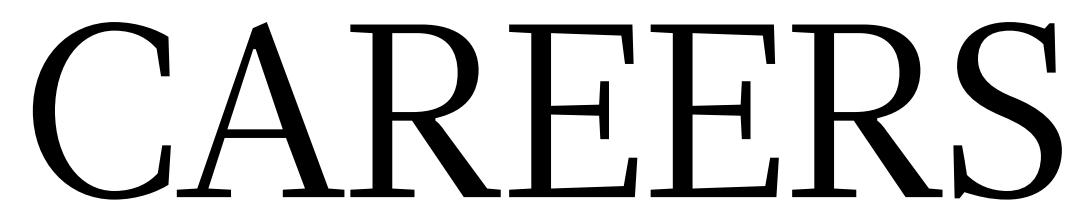

SPORTS AND SCIENCE How athletics trained a researcher go.nature.com/2k9cxrb

MENTAL HEALTH A collection on mental health in science careers go.nature.com/2yit7fk

NATURE CAREERS For the latest job
listings www.naturecareers.com

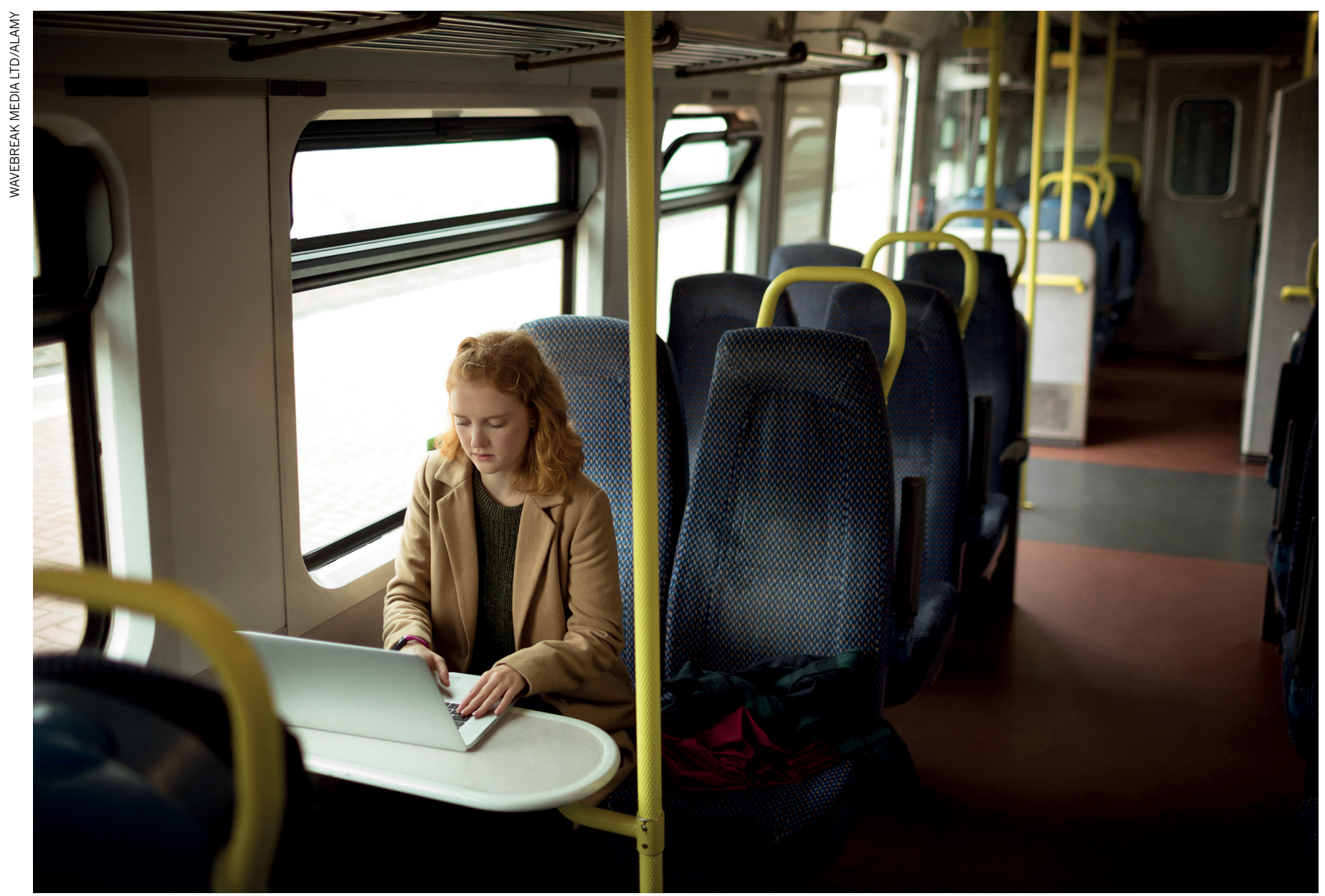

Travelling by train can reduce the environmental impact of attending a conference.

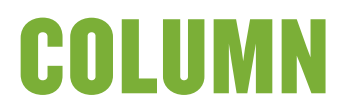

\section{Celebrate sustainable travel at conferences}

Universities should reward green travel practices when they make careerdefining decisions, say Olivier Hamant, Timothy Saunders and Virgile Viasnoff.

A 11 scientists face pressure to give external seminars and attend conferences. This is especially important for early-career researchers because doing so can help them to find new positions, and adds to their CVs. To do research effectively, scientists need to build networks and collaborations, and learn about cutting-edge developments in their field.

But the benefits need to be weighed against the environmental costs of attending conferences and meetings ${ }^{1}$. A return flight from London to New York (11,000 kilometres), for example, releases around 2 tonnes of carbon dioxide - roughly the same as that produced, on average, by a year's car usage in the European Union. Attending a conference generates an estimated 800 kilograms of $\mathrm{CO}_{2}$ emissions per participant.

From our experiences as junior and established faculty members in the biological 
- and physical sciences, the number of conferences seems to be increasing. This year, for example, Gordon Research Conferences one of the larger conference organizers in the life sciences - is running more than 300 meetings, compared with around 155 in 2000.

Here are seven practical proposals to reduce travel in academia, based on our own experiences of attending conferences and on discussions with colleagues:

\section{CUT DOWN ON MEETINGS}

Have fewer conferences and make them more valuable. Major organizers need to justify the meetings they run. One consequence of fewer meetings might be that the remaining conferences have stronger speaker lists; this would enable early-career researchers to meet more leading figures in their fields and build their academic networks, all while attending fewer meetings.

\section{POOL CONFERENCES}

Meeting organizers should establish agreed windows for particular fields each year. For instance, a series of conferences on different aspects of developmental biology could be held consecutively in, say, Heidelberg, Germany, then Wageningen, the Netherlands, and then Prague (or even in the same city). Speakers travelling long distances could cover multiple meetings in a single trip. Intercontinental travel to give one presentation would become the exception, not the norm. Alternatively, conferences could be longer and more in depth, such as the extended programmes and conferences that run for between three weeks and a few months held by the Kavli Institute for Theoretical Physics in Santa Barbara, California. Scientists would travel less often, but for longer. This does provide challenges, particularly for those with young

families, but we think that, combined with our first point, it would substantially reduce the total time travelling each year, while not adversely affecting career development.

\section{LEAD BY EXAMPLE}

Senior academics could attend fewer conferences and encourage junior lab members to take their place. To incentivize this, hiring and funding bodies could value transferred or declined conference invitations over a total number of invitations. Scientists who limit travel should be more attractive to a potential employer. This proposal does not necessarily reduce travel overall, but it promotes frugality and gives early-career researchers opportunities to build their careers. By becoming the champions

\section{"Major organizers need to justify the meetings they run."} of sustainability, senior and mid-career researchers could generate awareness and drive a systemic shift in scientific culture. We think this would encourage early-career researchers to reduce their own travel, without adversely affecting career prospects.

\section{USE TECHNOLOGY}

Although video conferencing is not as good as face-to-face meetings, it is improving and is time- and cost-efficient for both the audience and the speaker. Institutions and scientists should encourage junior researchers to present their work remotely.

\section{CONSIDER GREENER ALTERNATIVES}

Trains, for example, are much more environmentally friendly than flights, and should be the main form of transport across Europe. Yes, train travel takes longer and can be more

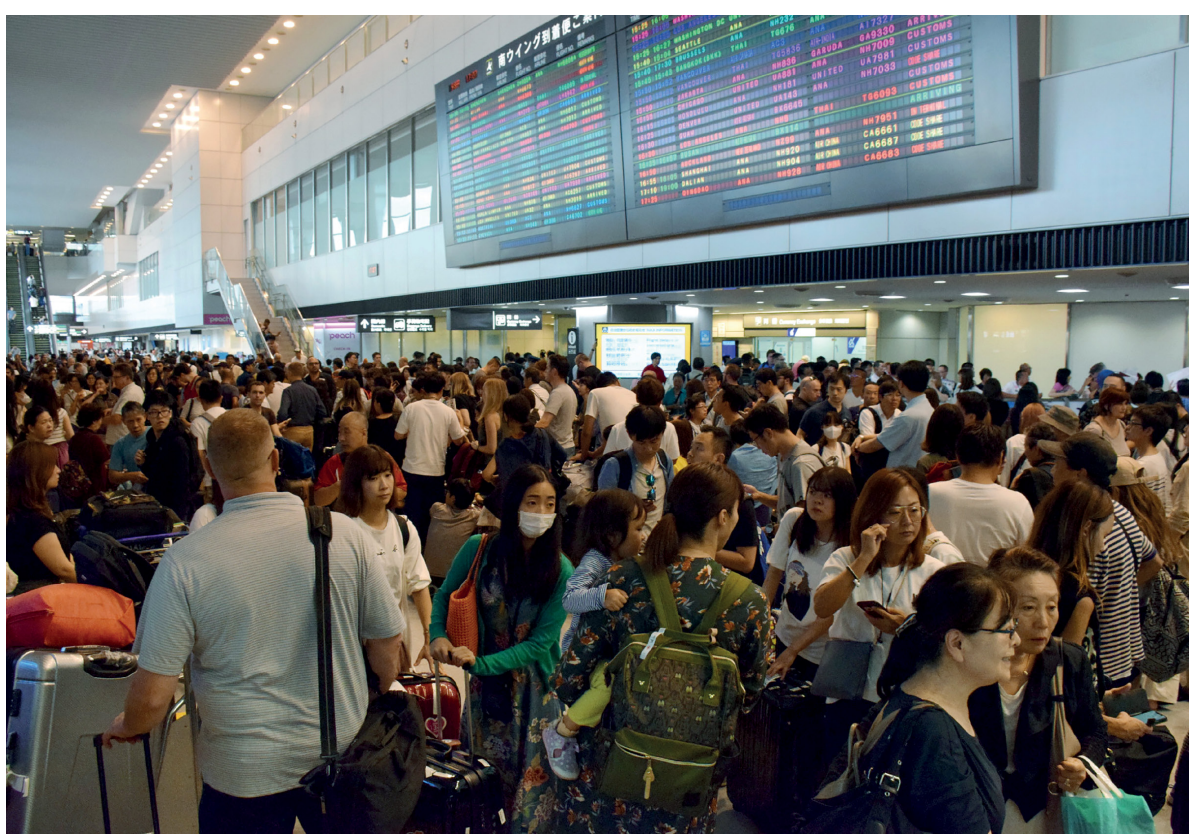

Busy airports aren't conducive to getting work done. expensive, but it's often easier to work on trains than on planes, and if there are fewer conferences, less time is spent travelling.

\section{GET CREATIVE}

It's not just about travel. Sustainability should be central to conferences. Organizers or attendees could serve or request low-impact food that might be vegetarian or locally sourced. Some conferences have already banned single-use plastics; others should follow their lead. The use of buses and other transport should be minimized (except where needed for accessibility), and walking encouraged if the event is spread across different locations - it's a great way to build relationships, and it's good for well-being ${ }^{2}$.

\section{SELF-REGULATE}

Finally, everyone should assess whether their travel is justified ${ }^{3}$. Each scientist could adopt an annual 'air mile' quota. Some scientists have even decided to give up air travel completely. A quota could encourage us to be more selective about the meetings we attend - do the career benefits outweigh the environmental costs? Researchers can also consciously support conferences and meetings that have specific policies to mitigate their environmental impact. Carbon offsetting is the easiest option available, and more organizers should do it. But this is only a stop-gap measure and is not sustainable long term - scientists must reduce their carbon footprint, not assuage their guilt.

We do not have clean hands, but we suggest these measures because people urgently need to reduce consumption ${ }^{4,5}$. Scientists face significant pressures to travel - a culture change is needed. Individuals can petition conference organizers, administrators and others in the community for an environmentally friendly scientific culture. Conferences are often organized and are always attended by researchers, so we do have the power to apply pressure and change organizations. Travel should not be an essential element of academic success; instead, evidence of sustainable travel should be valued in a researcher's career.

Olivier Hamant is a research director at the plant reproduction and development laboratory, National Institute for Agricultural Research (INRA), Lyon, France. Timothy Saunders is an assistant professor at the Mechanobiology Institute and in the department of biological sciences at the National University of Singapore. Virgile Viasnoff is an associate professor at the Mechanobiology Institute and the CNRS at the National University of Singapore. e-mail:dbsste@nus.edu.sg

1. Rozen, J. Nature 546, 565-567 (2017).

2. Spinellis, D. \& Louridas, P. PLOS ONE 8, e66508 (2013).

3. Grant, C. Ethnomusicol. Forum 27, 123-135 (2018)

4. Barnosky, A. D. et al. Nature 486, 52-58 (2012).

5. Steffen, W. et al. Proc. Natl Acad. Sci. USA 115, 8252-8259 (2018) 